\title{
Bacterial community compositions in sediment polluted by perfluoroalkyl acids (PFAAs) using Illumina high-throughput sequencing
}

\author{
Yajun Sun ${ }^{1,2} \cdot$ Tieyu Wang $^{1} \cdot$ Xiawei Peng ${ }^{1,2} \cdot$ Pei Wang ${ }^{1}$ Yonglong Lu ${ }^{1}$
}

Received: 30 June 2015 / Accepted: 4 January 2016 / Published online: 16 January 2016

(C) Springer-Verlag Berlin Heidelberg 2016

\begin{abstract}
The characterization of bacterial community compositions and the change in perfluoroalkyl acids (PFAAs) along a natural river distribution system were explored in the present study. Illumina high-throughput sequencing was used to explore bacterial community diversity and structure in sediment polluted by PFAAs from the Xiaoqing River, the area with concentrated fluorochemical facilities in China. The concentration of PFAAs was in the range of 8.44-465.60 ng/g dry weight $(\mathrm{dw})$ in sediment. Perfluorooctanoic acid (PFOA) was the dominant PFAA in all samples, which accounted for $94.2 \%$ of total PFAAs. High-level PFOA could lead to an obvious increase in relative abundance of Proteobacteria, $\varepsilon$ Proteobacteria, Thiobacillus, and Sulfurimonas and the decrease in relative abundance of other bacteria. Redundancy analysis revealed that PFOA played an important role in the formation of bacterial community, and PFOA at higher concentration could reduce the diversity of bacterial community. When the concentration of PFOA was below $100 \mathrm{ng} / \mathrm{g}$ $\mathrm{dw}$ in sediment, no significant effect on microbial community structure was observed. Thiobacillus and
\end{abstract}

Responsible editor: Robert Duran

Electronic supplementary material The online version of this article (doi:10.1007/s11356-016-6055-0) contains supplementary material, which is available to authorized users.

Tieyu Wang

wangty@rcees.ac.cn

1 State Key Lab of Urban and Regional Ecology, Research Center for Eco-Environmental Sciences, Chinese Academy of Sciences, Beijing 100085, China

2 College of Biological Sciences and Technology, Beijing Forestry University, Beijing 100083, China
Sulfurimonas were positively correlated with the concentration of PFOA, suggesting that both genera were resistant to PFOA contamination.

Keywords PFOA · Bacterial community structure $\cdot$ Illumina high-throughput sequencing $\cdot$ Redundancy analysis .

Thiobacillus $\cdot$ Sulfurimona

\section{Introduction}

Perfluoroalkyl acids (PFAAs), mostly known as perfluoroalkyl carboxylic acids (PFCAs) and perfluoroalkyl sulfonic acids (PFSAs), have unique physicochemical properties, such as high surface activity, thermal inertness, resistance to acidic and alkaline conditions, and amphiphilicity. These properties contribute their popularity for the application as surfactants, fire-fighting foams, pesticides, shampoos, oilresistant coating for carpets, car polishes, and food packaging materials for more than 60 years (Higgins et al. 2005; Paul et al. 2009). Perfluorooctanoic acid (PFOA) is one of the most widely detected PFCAs in various environmental media (river water, oceans, sediment, and soil) and tissues of wild animals and human (Ahrens et al. 2010; Dai et al. 2006; Higgins et al. 2005; Moody et al. 2002; Wang et al. 2013b). The application of PFOA is regulated in some developed countries such as USA and Canada, and PFOA manufacturing has been gradually phased out in these countries over the past few years. Even though their use is regulated, PFOA is still ubiquitous in the environment due to the huge demand for various products and industrial processes in some developing countries, especially in China (Wang et al. 2009; Wang et al. 2014c).

The widespread occurrence of PFOA has also caused increasing concern about its potential risk to organisms (Rayne and Forest 2009). The different toxic effects of PFOA towards 
human and animals have been explored, such as reproductive toxicity, developmental toxicity, carcinogenicity, and immunotoxicity in experimental animals (Lau et al. 2007; Olsen et al. 2009). Additionally, according to previous studies, PFOA could inhibit the growth and development of macrophytes (Hanson et al. 2005) and affect the survival of several invertebrates (Hazelton et al. 2012; Kawamoto et al. 2010). However, these toxicity studies of PFOA mainly focused on animals and plants, while the information on microorganisms is limited.

Bacterial communities are ubiquitous and have a crucial role in the biogeochemical cycling processes. Similarly, bacteria are the most diverse and abundant group in soil organisms (Acosta-Martinez et al. 2008). So it is essential to understand the association between bacterial community compositions and PFAA-polluted ecosystem. Environmental biodegradability of PFAAs by bacteria has been explored in previous studies, which focuses on microbial degradation pathways, defluorination potential, and novel degradation intermediates and products (Liu and Avendano 2013), but few studies were conducted to evaluate the toxicity of PFAAs to bacterial community. Meanwhile, various methods have been used to investigate bacterial compositions in sediment, including denaturing gradient gel electrophoresis (DGGE), cloning library of 16S rRNA genes, and fluorescence in situ hybridization (FISH) as well as terminal restriction fragment length polymorphism (T-RFLP). These conventional molecular biological methods lack sufficient sequences to capture systematic and comprehensive information on various microbial communities (Lu et al. 2012). With the development of the secondgeneration sequencing, recently, Illumina high-throughput sequencing technology has confirmed as a highly efficient tool for identifying the entire profile of microbial communities, which can characterize over $10^{7}$ reads in a single running through a paired-end sequencing approach (Matochko et al. 2012). This method has been widely used to analyze microbial compositions in various environmental samples, such as wastewater treatment plant (Ma et al. 2015), drinking water (Huang et al. 2014), and soil (Bartram et al. 2011). However, few studies have been conducted to analyze microbial communities in high PFOA-loading area by high-throughput sequencing.

In the present study, we selected the Xiaoqing River in Shandong Province of China as an area with fluorochemical industry for the investigation, and high PFOA loads were quantified (Wang et al. 2014b; Zhu et al. 2014). A total of 10 samples of surface sediment along the river were collected and sequenced using Illumina high-throughput platform. The objectives were: (1) to monitor the pollution status of PFAAs in sediment, (2) to uncover the bacterial community diversity and structure, and (3) to explore the relationship between bacterial community and environmental variables, especially PFOA contamination.

\section{Materials and methods}

\section{Site description and sample collection}

Xiaoqing River, with the length of $240 \mathrm{~km}$ and watershed area of $11,000 \mathrm{~km}^{2}$, is located in Shandong Province of China. In April 2014, 10 samples of surface sediment were collected from 10 sampling sites (XQ1-XQ10). The location and physicochemical properties for each site are shown in Fig. 1 and Table 1. It is worth noting that a major fluoropolymer manufacturer was identified at the upstream site XQ5 (Wang et al. 2014b). Sediment samples were harvested from four corners and the center point of each site with the area of $2 \mathrm{~m} \times 2 \mathrm{~m}$ using a sediment sampler (Peterson dredge, China). Surface sediment samples $(0-15 \mathrm{~cm})$ were carefully collected into $500 \mathrm{~mL}$ polypropylene (PP) bottles and mixed to produce one composite sample for each site. The sediment samples were stored in ice box and transferred to the laboratory immediately. One part was stored at $-80^{\circ} \mathrm{C}$ before DNA extraction, the other part was dried in a FreeZone 2.5 Liter Benchtop Freeze Dry System (LABCONCO, Kansas City, MO), and ground to pass a 2-mm mesh sieve before further analysis.

\section{Determination of PFAAs}

\section{Sample extraction and analysis}

Sediment samples were extracted according to a previously published method with minor optimizations and modifications (Naile et al. 2010; Wang et al. 2013b; Zhu et al. 2014). A total of 12 PFAAs, including 9 PFCAs (perfluorobutanoic acid (PFBA), perfluoropentanoic acid (PFPeA), perfluorohexanoic acid (PFHxA), perfluoroheptanoic acid (PFHpA), perfluorooctanoic acid (PFOA), perfluorononanoic acid (PFNA), perfluorodecanoic acid (PFDA), perfluoroundecanoic acid (PFUdA), perfluorododecanoic acid (PFDoA)), and 3 PFSAs (potassium perfluorobutanesulfonate (PFBS), sodium perfluorohexanesulfonate (PFHxS), potassium perfluorooctanesulfonate (PFOS)) were analyzed (Wang et al. 2014b). Briefly, 2-g sediment was placed in a 50-mL PP centrifuge tube and spiked with mass-labeled internal standards (5 ng). Then, the sediment samples were digested with $2 \mathrm{~mL}$ of $100 \mathrm{mM} \mathrm{NaOH}$ in acetonitrile (ACN) and subjected to sonication for $30 \mathrm{~min}$. The mixture was shaken at $250 \mathrm{rpm}$ for $30 \mathrm{~min}$ after adding $20 \mathrm{~mL}$ of acetonitrile. Subsequently, $0.1 \mathrm{~mL}$ of $2 \mathrm{~mol} / \mathrm{L}$ hydrochloric acid was added and the mixture was centrifuged at $3000 \mathrm{rpm}$ for $15 \mathrm{~min}$. The supernatant was transferred to another $50 \mathrm{~mL}$ centrifuge tube. The above steps were repeated once except that $10 \mathrm{~mL}$ acetonitrile was added instead of $20 \mathrm{~mL}$. Finally, the supernatant was pooled and evaporated to $1 \mathrm{~mL}$ under a gentle flow of nitrogen with high purity ( $99.999 \%$, Haidian District, BJ). The extracts were further loaded onto pre-cleaned ENVI-Carb tubes and 


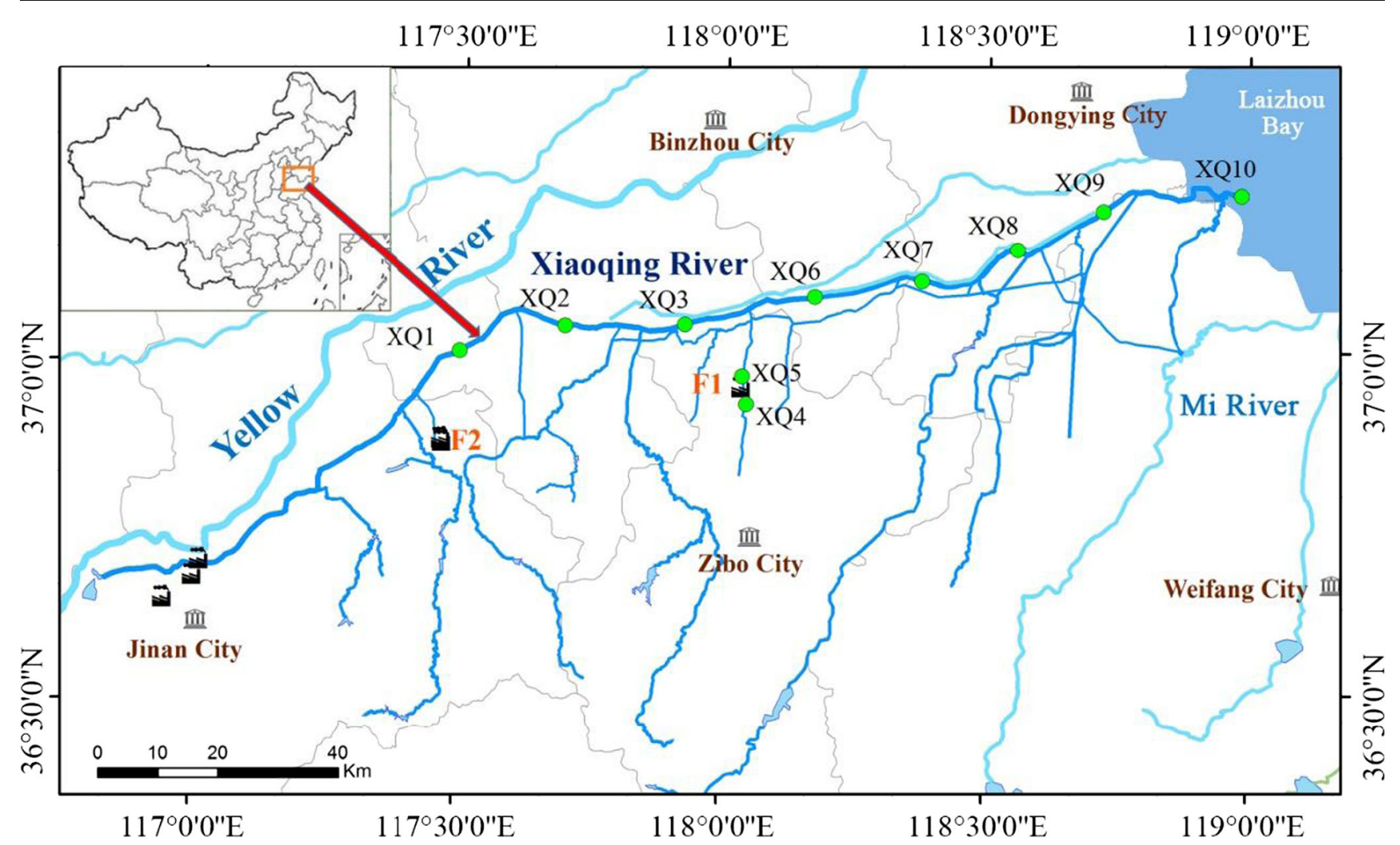

Fig. 1 Sediment sampling sites along the Xiaoqing River, Shandong Province of China

purified with OASIS-WAX cartridges. After loading, cartridges were washed with $4 \mathrm{~mL}$ of $25 \mathrm{mM}$ ammonium acetate and air-dried. Then, $4 \mathrm{~mL}$ of methanol and $4 \mathrm{~mL}$ of $0.1 \%$ $\mathrm{NH}_{4} \mathrm{OH}$ in methanol were added to cartridges to wash the target analytes. The sample volume was reduced to $1 \mathrm{~mL}$ under high purity nitrogen and filtered through $0.2 \mathrm{~mm}$ nylon filter, and then it was transferred into a $1.5-\mathrm{mL}$ PP snap top brown glass vial with polyethylene (PE) septa for further analysis. The instrumental analysis was implemented via Agilent 1290 high performance liquid chromatography system equipped with an Agilent 6460 Triple Quadrupole LC/MS
System (Agilent Technologies, Palo Alto, CA) that was operated in a negative electrospray ionization (ESI) mode. The HPLC and ESI-MS instrument conditions were listed in Table S1.

\section{Quality assurance and quality control}

During collection and extraction, samples were kept away from any fluorinated materials to avoid contamination. Besides, transport blanks, field blanks, procedure blanks, and solvent blanks were conducted with every sample set.
Table 1 Physicochemical properties of each sampling point

\begin{tabular}{lrrrrrrrrrr}
\hline & XQ1 & XQ2 & XQ3 & XQ4 & XQ5 & XQ6 & XQ7 & XQ8 & XQ9 & XQ10 \\
\hline Temperature $\left({ }^{\circ} \mathrm{C}\right)$ & 21.9 & 21.8 & 21.3 & 23.9 & 23.8 & 24.3 & 22.3 & 22.5 & 19.9 & 19.9 \\
DO $(\mathrm{mg} / \mathrm{L})$ & 6.8 & 8.8 & 8.8 & 10.3 & 7.7 & 7.5 & 12.9 & 9.4 & 9.8 & 10.5 \\
Conductivity $(\mathrm{mS} / \mathrm{cm})$ & 1.5 & 1.4 & 1.8 & 6.8 & 6.5 & 2.7 & 3.3 & 2.8 & 7.0 & 28.8 \\
Salinity (\%o) & 0.8 & 0.7 & 1.0 & 3.8 & 3.6 & 1.4 & 1.8 & 1.5 & 4.3 & 19.9 \\
$\mathrm{pH}$ & 7.7 & 7.8 & 7.6 & 7.7 & 7.9 & 7.9 & 7.8 & 8.0 & 8.2 & 8.0 \\
TOC (g/kg) & 20.8 & 19.4 & 13.7 & 20.3 & 14.5 & 21.5 & 20.6 & 16.2 & 17.8 & 7.3 \\
TN & 1.4 & 0.9 & 1.4 & 0.8 & 0.4 & 1.4 & 0.8 & 1.3 & 0.7 & 0.3 \\
TP & 1.5 & 1.0 & 1.2 & 1.38 & 0.5 & 1.4 & 0.9 & 0.7 & 0.51 & 0.5 \\
Moisture (\%) & 38.4 & 36.0 & 42.6 & 30.3 & 43.3 & 47.1 & 39.4 & 30.4 & 28 & 26.9 \\
Clay (\%) & 12.7 & 13.0 & 13.7 & 17.1 & 11.2 & 15.2 & 11.3 & 8.6 & 15 & 10.7 \\
Powder (\%) & 42.2 & 43.5 & 45.0 & 38.1 & 40.1 & 36.9 & 50.9 & 21.6 & 28.8 & 34.4 \\
Sand (\%) & 45.1 & 43.5 & 41.3 & 44.8 & 48.7 & 48 & 37.7 & 69.7 & 56.2 & 54.9 \\
\hline
\end{tabular}


Nine-point internal standard curves with native standards ranging from 0.01 to $100 \mathrm{ng} / \mathrm{mL}$ and internal standards of $5 \mathrm{ng} / \mathrm{mL}$ were prepared for the quantification of individual PFAA with determination coefficients $\left(r^{2}\right)$ for all target analytes over 0.99 . The limit of detection (LOD) and limit of quantification (LOQ) were defined as the peak of analytes to yield a signal-to-noise $(\mathrm{S} / \mathrm{N})$ ratio of $3: 1$ and 10:1, respectively. Matrix spiked recovery rates ranged from 75 to $117 \%$. No detectable PFAA was observed exceeding LOQ in all fields, transport, and solvent blanks. Detailed QA/QC measurements of PFAAs in sediment samples were listed in Table S2.

\section{Microbial analysis}

\section{DNA extraction, PCR amplification, and sequencing}

DNA was extracted from sediment samples with the FastDNA $^{\mathrm{TM}}$ SPIN Kit for Soil (MP Biomedicals, USA) following the manufacturer's protocols. The concentrations of extracted DNA were determined through Nanodrop Spectrophotometer ND-1000 (Thermo Fisher Scientific, USA). Additionally, the extracted DNA was evaluated by $1.5 \%$ agarose gel electrophoresis and stored at $-20{ }^{\circ} \mathrm{C}$ prior to further analysis.

Taxonomic profiling of the sediment microbial community was performed using Illumina ${ }^{\circledR}$ MiSeq sequencing combinatorial sequence-tagged PCR products. The 515F (5'GTGCCAGCMGCCGCGGTAA-3') and 806R (5'GGACTACHVGGGTWTCTAAT-3') primers with different barcodes were used to amplify bacteria specific V4 hyper variable region of the 16S rRNA gene (Bates et al. 2011). PCR amplification was conducted in a reaction system $(30 \mu \mathrm{L})$ containing $15 \mu \mathrm{L}$ Phusion ${ }^{\circledR}$ High-Fidelity PCR Master Mix with GC buffer (New England Biolabs, USA), $0.2 \mu \mathrm{M}$ of forward and reverse primers, and $10 \mu \mathrm{L}$ of template DNA. PCR program included initial denaturation at $98^{\circ} \mathrm{C}$ for $1 \mathrm{~min}$, followed by 30 cycles of $98^{\circ} \mathrm{C}$ for $10 \mathrm{~s}$, annealing at $50{ }^{\circ} \mathrm{C}$ for $30 \mathrm{~s}$, and extension at $72^{\circ} \mathrm{C}$ for $60 \mathrm{~s}$, with a final elongation at $72{ }^{\circ} \mathrm{C}$ for $5 \mathrm{~min}$. The PCR products were pooled and purified using Gene JET Gel Extraction Kit (Thermo Scientific). Finally, the DNA library was constructed and run on an Illumina MiSeq platform and $250 \mathrm{bp} / 300 \mathrm{bp}$ paired-end reads were generated.

\section{Sequence and microbial community analysis}

Paired-end reads were merged by using Flash (Magoc and Salzberg 2011), and the low quality sequences were removed (http://qiime.org/scripts/split libraries fastq.html). Chimera was detected by UCHIME, and the resultant high quality sequences were grouped into operational taxonomic units, at a $97 \%$ sequence similarity threshold, using the UPARSE program (Edgar 2013) in the QIIME (V1.6.0, http://qiime. org/index.html) software package. The taxonomic assignment was performed with the Ribosomal Database Project (RDP) classifier with minimum confidence of $80 \%$. We subsampled the DNA sequences, so for comparative analysis, the samples contained the same number of sequences. We also rarified the OTU table to compute community richness estimators of Chaol and ACE, community diversity estimators of Shannon and Simpson and the Good's coverage, and Rarefaction curves were generated based on these three metrics. In order to describe the similarity and difference among 10 samples and detect the relationship among samples, environmental factors and bacterial richness/diversity revealed by sequencing of $16 \mathrm{~S}$ rRNA. Redundancy analysis (RDA) (Gao et al. 2014), a direct gradient analysis, was constructed based on unweighted UniFrac metric with CANOCO5.0.

\section{Statistical analysis}

Statistical analysis was performed with IBM SPSS Statistics V21 (SPSS Inc. Quarry Bay, HK). Before the analysis of PFAAs, concentrations less than LOQs were set to one-half of the LOQs, and those less than LODs were assigned as values of LODs $/ \sqrt{ } 2$ (Bao et al. 2011). Spearman correlation coefficients (Puth et al. 2015) were calculated to assess the association among environmental factors.

\section{Results and discussion}

\section{PFAAs in sediment samples from Xiaoqing River}

The concentrations of PFAAs in sediment samples from Xiaoqing River are shown in Fig. 2. The total concentration of PFAAs in surface sediment ranged from 8.44 to $465.60 \mathrm{ng} /$ $\mathrm{g}$ dry weight (dw) with a mean of $109.47 \mathrm{ng} / \mathrm{g}$ dw. PFOA was the dominant PFAAs and ranged from 3.86 to $456.20 \mathrm{ng} / \mathrm{g} \mathrm{dw}$ with a mean concentration of $103.14 \mathrm{ng} / \mathrm{g} \mathrm{dw}$ and with the contribution rate of $94.2 \%$ to total PFAAs, which was followed by PFOS ( 0.40 to $5.16 \mathrm{ng} / \mathrm{g} \mathrm{dw}, 1.49 \mathrm{ng} / \mathrm{g} \mathrm{dw}$ on average, $1.35 \%)$ and short chain PFCAs, including PFBA (0.04 to $14.45 \mathrm{ng} / \mathrm{g} \mathrm{dw}, 1.98 \mathrm{ng} / \mathrm{g} \mathrm{dw}$ on average, $1.8 \%$ ), PFHxA (0.02 to $2.98 \mathrm{ng} / \mathrm{g} \mathrm{dw}, 0.78 \mathrm{ng} / \mathrm{g} \mathrm{dw}$ on average, $0.71 \%$ ), PFHpA (0.02 to $1.23 \mathrm{ng} / \mathrm{g} \mathrm{dw}, 0.64 \mathrm{ng} / \mathrm{g} \mathrm{dw}$ on average, $0.59 \%$ ), and PFPeA (0.04 to $1.06 \mathrm{ng} / \mathrm{g} \mathrm{dw}, 0.39 \mathrm{ng} / \mathrm{g} \mathrm{dw}$ on average, $0.36 \%$ ). For concentrations of the other long chain PFCAs and other short chain PFSAs, the total contribution was less than $1 \%$. The highest concentrations of total PFAA (465.60 ng/g dw) and PFOA (456.20 ng/g dw) were observed in sample XQ5 (Fig. 2). These results suggested that the dominant PFAA in sediment was PFOA, which is similar to the previous report (Wang et al. 2014b). 
Fig. 2 Concentrations of PFAAs in sediment samples from Xiaoqing River

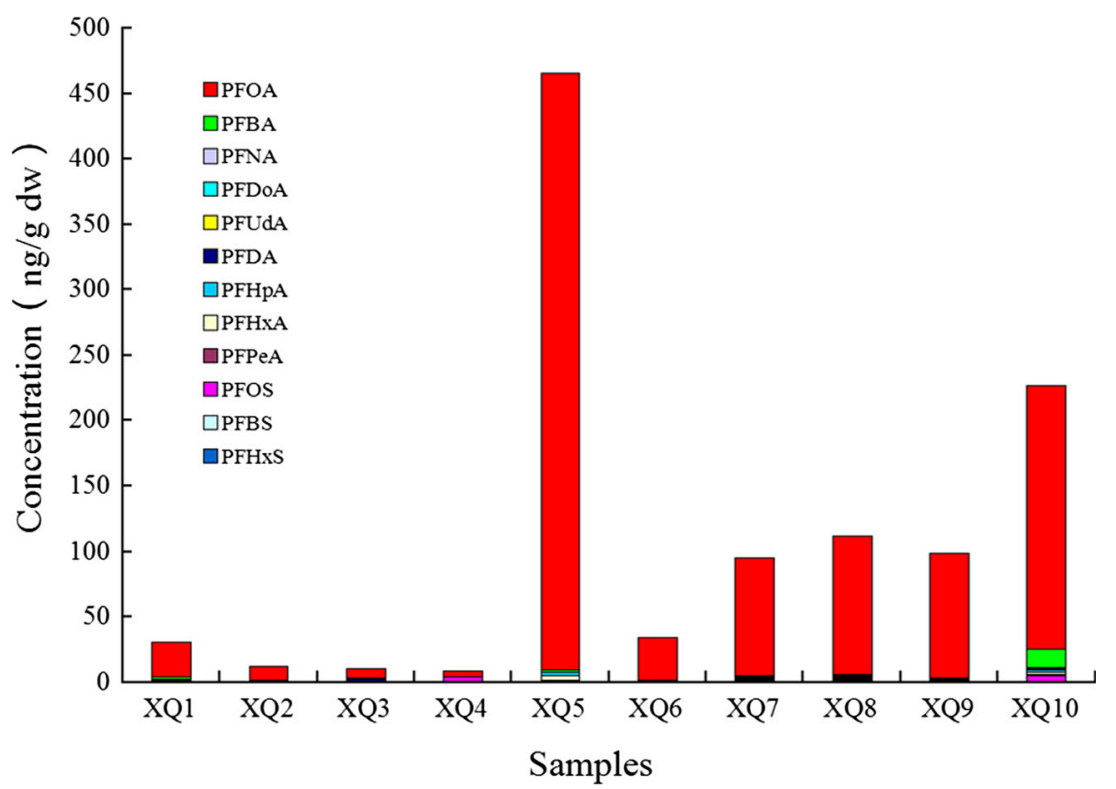

Sediment samples from Xiaoqing River contained extremely high concentration of PFOA (a maximum of $456.20 \mathrm{ng} / \mathrm{g} \mathrm{dw}$ ) when compared with other riverine and coastal sediment studies in both China and other countries, such as North Bohai coastal rivers (n.d. $-0.54 \mathrm{ng} / \mathrm{g} \mathrm{dw}$ ) (Wang et al. 2011), South Bohai coastal rivers (0.01$1.05 \mathrm{ng} / \mathrm{g} \mathrm{dw}$ ) (Zhu et al. 2014), Zhujiang River in Guangzhou, China (0.09-0.28 ng/g dw) (Bao et al. 2010), Western coast of Korea $(<0.20-2.40 \mathrm{ng} / \mathrm{g} \mathrm{dw}$ ) (Naile et al. 2013), Kyoto area River, Japan (1.31-3.92 ng/g dw) (Senthilkumar et al. 2007), Ganges River of India $(<0.50$ $14.09 \mathrm{ng} / \mathrm{g} \mathrm{dw}$ ) (Corsolini et al. 2012), Roter Main River, Germany (0.02-0.07 ng/g dw) (Becker et al. 2008), and San Francisco Bay, USA (nd-0.40 ng/g dw) (Higgins et al. 2005). High level of PFOA in sediment especially at sample XQ5 implied local point source in this area, and the manufacturing facility had been proven in the upstream of XQ5 (Wang et al. $2014 \mathrm{~b}$ ), which produced an annual capacity of 50,000 tons of TFE, 37,000 tons of PTFE, 10,000 tons of hexafluoropropylene (HFP), and more than 200,000 tons of different types of fluorinated refrigerants by the end of 2012 .

\section{Bacterial community compositions}

Illumina high-throughput sequencing was conducted to explore bacterial community diversity and structure of Xiaoqing River. After trimming the barcodes, adapters, and primers and filtering the low quality sequences, totally 612 , 615 reads for 10 samples were obtained. The chimeras in the sequencing reads were further removed. Totally, 35,135-114, 367 effective sequences for these samples were obtained (Table 2).

\section{Richness and diversity of microbial community}

Biodiversity of 10 sediment samples was investigated based on the analysis of OTUs, Chao1, ACE, Good's coverage, Shannon and Simpson at cutoff level of $3 \%$ (Table 2). Results showed that OTU numbers of these samples ranged from 2319 to 4878 based on the effective sequences, and XQ6 had the richest diversity (4878 OTUs), whereas XQ5 displayed the lowest richness (2319 OTUs). The patterns of Chaol and ACE were accordant with the estimation of OTUs, and XQ5 had lower community richness while XQ6 had higher community richness. According to two diversity indices (Shannon and Simpson), sample XQ5 had lower community diversity (6.76 and 0.0711$)$ compared to the other samples with indices of 8.58-9.89 and 0.0030.0185 , respectively (Table 2 ). The diversity and richness of sediment samples from Xiaoqing River were similar to intertidal sediment samples from Laizhou Bay of Bohai Sea (Wang et al. 2013a; Wang et al. 2014a). Numerous studies showed that the ecosystem of the Bohai Sea in its coastal environment was heavily polluted and was one of the most degraded areas in China (Ma et al. 2001; Yu and Mao 2002; Zhang et al. 2009). The ecosystem of Xiaoqing River has suffered from serious damage and the contaminants mainly come from fluorine chemical industry (Hong et al. 2010; Ongley et al. 2010). Other pollutants have not been reported from the Xiaoqing River; therefore, the lower bacterial diversity in the sediment from the Xiaoqing River is possibly more similar to that in the highly polluted sediment from the Laizhou Bay of the Bohai sea due to both sites being highly contaminated which in the case of the Xiaoqing River is due to PFAAs. 
Table 2 The richness and diversity of bacterial community

\begin{tabular}{llllllll}
\hline Sample ID & $\begin{array}{l}\text { Number of } \\
\text { sequences }\end{array}$ & OTU & Chao 1 & ACE & $\begin{array}{l}\text { Good's } \\
\text { coverage }\end{array}$ & Shannon & Simpson \\
\hline XQ1 & 101,031 & 4468 & 3433.5 & 5731.7 & $96.9 \%$ & 9.53 & 0.0059 \\
XQ2 & 45,160 & 3174 & 2957.6 & 5087.9 & $94.2 \%$ & 9.37 & 0.0054 \\
XQ3 & 36,135 & 2629 & 2608.9 & 4673.6 & $90.3 \%$ & 8.53 & 0.0185 \\
XQ4 & 36,388 & 2977 & 2999.7 & 5963.2 & $93.3 \%$ & 9.05 & 0.0075 \\
XQ5 & 35,181 & 2319 & 2508.7 & 4258.2 & $95.1 \%$ & 6.76 & 0.0711 \\
XQ6 & 114,367 & 4878 & 3809.8 & 5798.9 & $97.4 \%$ & 9.44 & 0.0095 \\
XQ7 & 80,290 & 4344 & 3646.5 & 5199.8 & $96.3 \%$ & 9.65 & 0.0042 \\
XQ8 & 19,117 & 2697 & 2858.2 & 5621.1 & $89.8 \%$ & 9.89 & 0.0030 \\
XQ9 & 36,846 & 3445 & 3549.2 & 5706.4 & $92.8 \%$ & 9.60 & 0.0067 \\
XQ10 & 91,437 & 3975 & 3279.5 & 5143.3 & $97.1 \%$ & 8.83 & 0.0095 \\
\hline
\end{tabular}

Chao 1 - community richness. A higher number represents more richness

$\mathrm{ACE}$ - community richness. A higher number represents more richness

Coverage - sampling depth

Shannon - community diversity. A higher number represents more diversity

Simpson - community diversity. A higher number represents less diversity

\section{Abundance profiles for phylum and classes}

The phylogenetic classification of bacterial 16S rRNA sequences from 10 sediment samples is shown in Fig. 3 based on phylum and in Table $\mathrm{S} 3$ based on classes. Figure 3 showed that the most abundant and largest phylum was Proteobacteria with $59.42 \%$ of the sequences on average (minimum $50.4 \%$ in XQ1 and maximum $85.1 \%$ in XQ5). Previous studies have shown that Proteobacteria is the prominent phylum in sediment from a drinking water reservoir (Roeske et al. 2012) and intertidal zones of Bohai Bay (Wang et al. 2013a), industrial wastewaters from steel industrial (Ma et al. 2015), pharmaceutical, petroleum refinery and sewage (Ibarbalz et al. 2013), soils of livestock-cotton production (Acosta-Martinez et al. 2010), and $\mathrm{CO}_{2}$ gas vent (Saenz de Miera et al. 2014). Moreover, the abundance of Proteobacteria was higher when environmental conditions were aggravated, such as an increasing abundance of Proteobacteria in drinking water after chlorine disinfection (Huang et al. 2014) and river sediment after huge nitrate injection (Chen et al. 2013). Consistent with previous studies, Proteobacteria occupied an obviously higher percentage in sample XQ5 (85.1\%) with serious pollution of PFOA than that in other samples with a range from 50.4 to $68.6 \%$. The
Fig. 3 Bacterial community compositions at phylum level in each sample

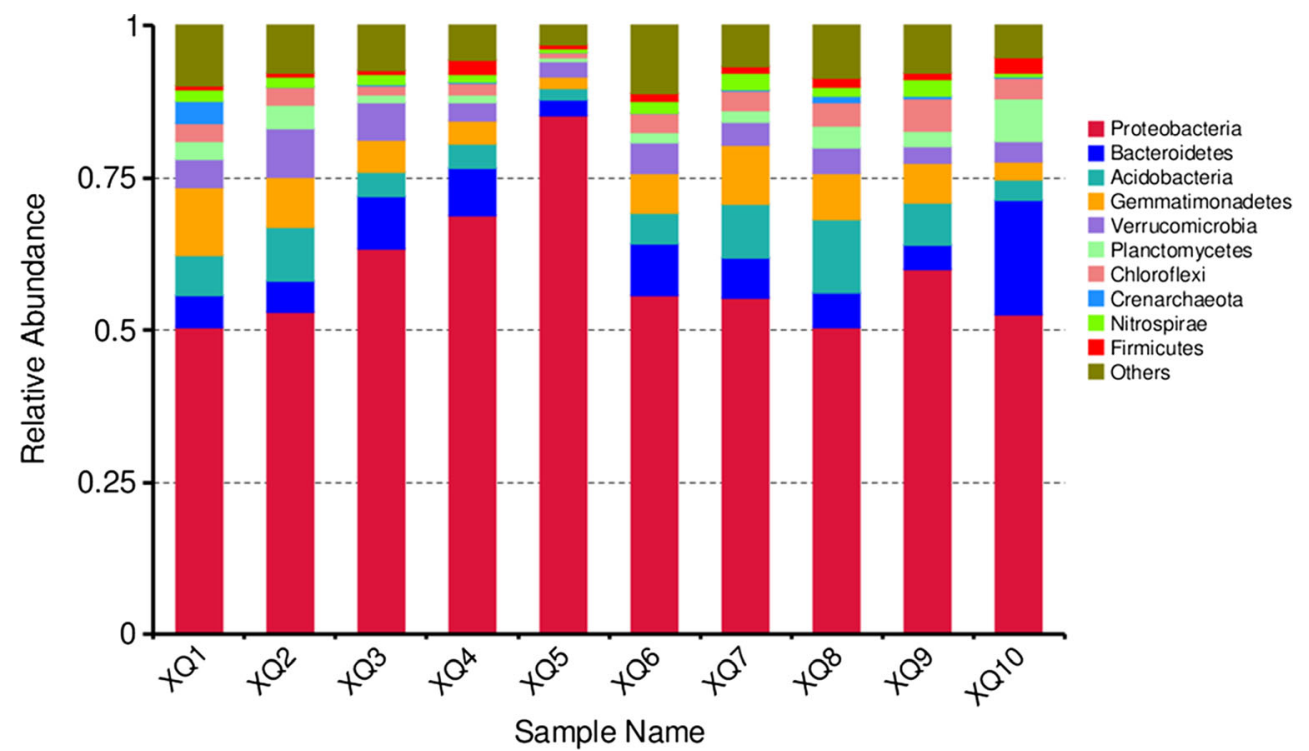


following major phyla were Bacteroidetes (2.5-18.7\%), Gemmatimonadetes (1.9-11.1\%), Acidobacteria (2.0$12.0 \%)$, Verrucomicrobia (2.3-8.0\%), and Chloroflexi $(0.8-5.2 \%)$.

At the class level, distinctly higher relative abundances of sequences affiliated with the classes of Flavobacteria and $\alpha$-Proteobacteria were observed (15.8 and $13.9 \%$ ) in sample XQ10 (Table S3). A large number of studies have shown that Flavobacteria is abundant in the sea (Abell and Bowman 2005; Zamora et al. 2013), that is consistent with the position of XQ10 located in the estuary (Fig. 1).

Among all freshwater sediment samples, there was considerable consistency between bacterial communities except at site XQ5. For all freshwater sediment samples except XQ5, $\beta$-Proteobacteria was the most prevalent class with relative abundance in samples ranging from 17.1 to $31.9 \%$ (Table S3). The second and third prominent classes in all freshwater sediment but XQ5 were $\gamma$ Proteobacteria and $\delta$-Proteobacteria with relative abundance ranging from 15.7 to $24.5 \%$ and 6.0 to $10.9 \%$. Except for three subdivisions of Proteobacteria, other major classes contained Gemmatimonadetes-1 (2.6 to $8.2 \%$ ), $\alpha$-Proteobacteria (1.9 to $5.8 \%$ ), Sphingobacteria (1.4 to $3.3 \%$ ), and Pedosphaerae (1.1 to $4.1 \%$ ). As for XQ5, $\beta$ Proteobacteria (39.1\%) was still the largest class, while the second and third prominent classes were $\varepsilon$ Proteobacteria $(23.4 \%)$ and $\gamma$-Proteobacteria (16.4\%). $\varepsilon$-Proteobacteria, as the second major class in sample XQ5, was obviously higher than that in other freshwater sediment samples with a range from 0.6 to $1.7 \%$. This is different from the results of microbial community in freshwater sediments (Roeske et al. 2012; Wang et al. 2012), which showed that $\beta$-, $\delta$-, and $\gamma$-Proteobacteria were the major abundant types of Proteobacteria. Other major classes in sample XQ5 contained $\delta$ Proteobacteria $(3.7 \%)$, $\alpha$-Proteobacteria (2.2\%), Verrucomicrobiae (1.4\%), and Gemmatimonadetes-1 $(1.3 \%)$. These findings suggest that elevated PFAAs in sediment cause a shift in the bacterial community towards E-Proteobacteria.

\section{Identification of the core genera}

A total of 455 genera were identified in 10 sediment samples. Only 94 genera were shared by all samples, whereas these genera represented $92.5 \%$ of the total identified sequences. Percentage of the most abundant genus in each sample is shown in Table 3. In sample XQ10, the dominant genera were Lutimonas, Marinobacter, Aequorivita, Luteolibacter, and Shewanella with $4.8,3.2,2.1,1.6$, and $1.1 \%$, respectively, which were all reported as marine bacteria. Lutimonas, as the core genus, was known to be an important member of the bacterial community in many aquatic environments and has a special role in using high molecular mass dissolved organic matter (Kirchman 2002). Thiobacillus (22.9\%), Sulfurimonas (21.9\%), and Dok59 (1.6\%) were the dominant genus and represented half of the sequences at XQ5 (Table 3), while the percentage of genera was very low (almost all $<0.6 \%$ ). In other freshwater sediment samples, the dominant genera were similar, mainly including Thiobacillus (1.5-6.8\%), Dok59 (1.2-4.4\%), and Candidatus solibacter $(0.8-1.3 \%)$. Although Thiobacillus was the dominant genus in all freshwater sediment samples, it was more prevalent in the sediment at XQ5 (Table 3), while it was only up to $1.5-6.8 \%$ of the community at the other sites.

Thiobacillus is a genus found in water, air, soil (Vidyalakshmi et al. 2009), sewage pipelines (Roberts et al. 2002), and even degraded concrete structure (Okabe et al. 2007). Most species of Thiobacillus use ammonium salt as nitrogen source (Allegretti et al. 2006; Nikolov et al. 2002; Yousefi et al. 2014), and some of them are capable of denitrification that can reduce the content of nitrogen in the soil nutrition (Torrentó et al. 2010). Based on the reported functional role of Thiobacillus in soil, the lower total nitrogen recorded at XQ5 may be potentially due to metabolic activity of this genus. The higher prevalence of Thiobacillus and Sulfurimonas at XQ5 suggests that the growth of Thiobacillus and Sulfurimonas may be promoted under certain PFOA concentrations, or the two bacteria may have resistance to high concentration of PFOA, which needs to be further explored.

\section{Relationship between environmental factors and community structure}

After Spearman correlation analysis among environmental factors (Table S4), and RDA screening between environmental factors and bacterial community, three environmental factors (TOC, salinity, and PFOA) were displayed as the important factors for affecting bacterial community structure. Then, RDA analysis (Gao et al. 2013) was conducted to explore the possible correlation between bacterial community structure and major environmental variables. Three environmental variables were all significant according to the permutation test analysis $(p<0.05)$. The length of the arrows in the RDA plot corresponds with the strength of the correlation between variables and community structure.

As shown in Fig. 4, the first and second canonical axes represented 47.2 and $24.4 \%$ of variation, respectively. RDA analysis at the genus level showed that the bacterial communities in 10 sediment samples were clustered into 3 distinct groups including group I (XQ5), group II (XQ10), and group III (sample points except XQ5 and XQ10). XQ5 and XQ10 were separated from others, suggesting the clear distinct structures of microbial community among three groups. Group I (XQ5), with the highest concentrations of PFOA (456.2 ng/g 
Table 3 Percentage of the most abundant genus in each sample $(\%)$

\begin{tabular}{lcccccccccc}
\hline & XQ1 & XQ2 & XQ3 & XQ4 & XQ5 & XQ6 & XQ7 & XQ8 & XQ9 & XQ10 \\
\hline Thiobacillus & 1.53 & 2.22 & 6.84 & 4.52 & 22.91 & 4.40 & 2.27 & 2.41 & 6.49 & 1.07 \\
Sulfurimonas & 0.42 & 0.61 & 0.88 & 1.00 & 21.10 & 0.43 & 0.34 & 0.40 & 0.75 & 0.28 \\
Dok59 & 2.30 & 2.36 & 3.39 & 1.89 & 1.58 & 4.44 & 1.97 & 1.14 & 1.72 & 0.72 \\
Lutimonas & 0.04 & 0.17 & 0.09 & 0.13 & 0.11 & 0.30 & 0.36 & 0.26 & 0.18 & 4.81 \\
Marinobater & 0.16 & 0.24 & 0.16 & 0.16 & 0.14 & 0.46 & 0.51 & 0.38 & 0.42 & 3.16 \\
Aequorivita & 0.04 & 0.08 & 0.07 & 0.03 & 0.05 & 0.14 & 0.17 & 0.14 & 0.07 & 2.13 \\
Rubrivivax & 0.22 & 0.32 & 0.23 & 0.38 & 0.34 & 0.42 & 2.00 & 0.44 & 0.49 & 0.26 \\
Luteolibacter & 0.40 & 1.72 & 0.86 & 0.20 & 0.15 & 0.69 & 0.65 & 0.42 & 0.31 & 1.58 \\
Candidatus Solibacter & 1.04 & 0.83 & 0.87 & 0.77 & 0.31 & 0.85 & 0.79 & 1.40 & 1.00 & 0.33 \\
Sulfuritalea & 0.78 & 0.96 & 1.41 & 1.10 & 0.56 & 0.73 & 0.43 & 0.29 & 0.49 & 0.19 \\
\hline
\end{tabular}

dw) (Fig. 2), had the lowest diversity, with a Shannon index of 6.76 and a Simpson index of 0.071. At the site of XQ5, PFOA was the most important environmental factor affecting the bacterial community structure based on RDA analysis. Group II (XQ10) was located in the estuary of Xiaoqing River, while other samples were from freshwater, so its bacterial community was mainly affected by salinity. Other sites clustered together forming group III, the community structure at sites in group III was mainly effected by TOC and there was no significant effect by PFOA based on RDA analysis. These findings suggest that PFOA concentrations below $100 \mathrm{ng} / \mathrm{g}$ do

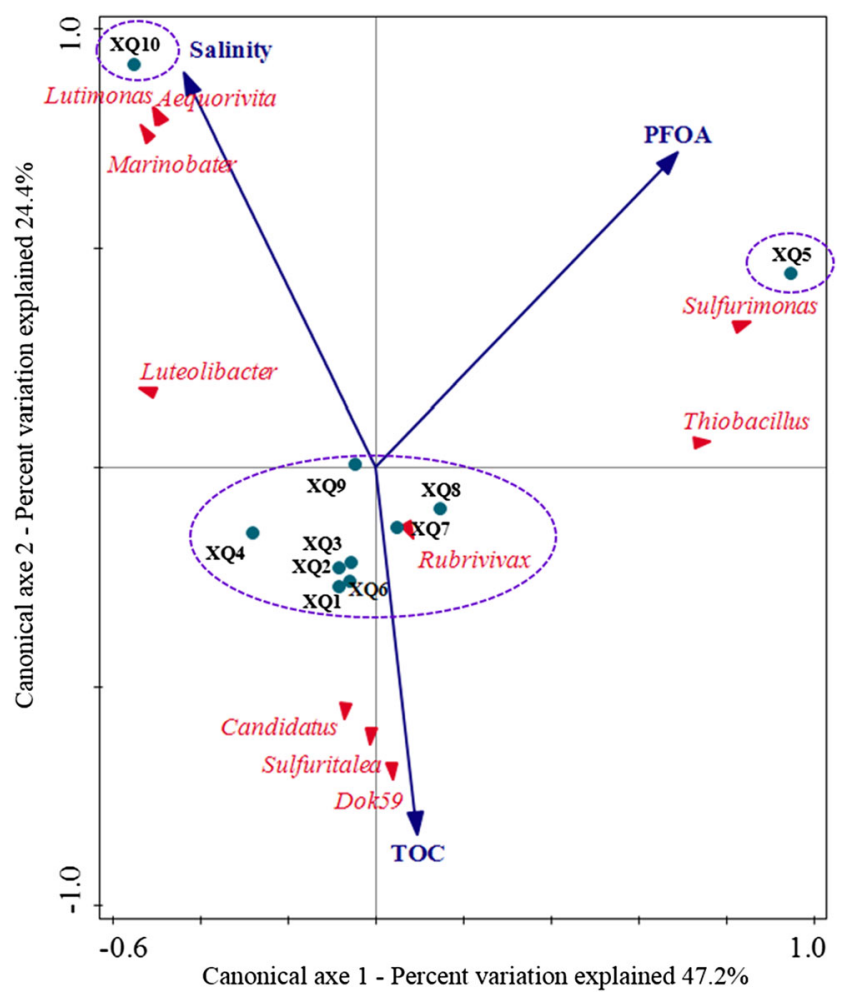

Fig. 4 Redundancy analysis triplot to explore the correlation between sediment properties and bacterial community based on genus level structure not result in the impact on the microbial community structure. The grouping pattern indicated that PFOA played an important role in community formation, and high concentration of PFOA could reduce the diversity of bacterial community. When the concentration of PFOA was below $100 \mathrm{ng} / \mathrm{g}$, no significant effect on microbial community structure was observed.

Triplot analysis suggested that the dominant genera of Sulfurimonas and Thiobacillus confined to XQ5 were positively correlated with the concentration of PFOA, while the genera of C. solibacter, Sulfuritalea, Dok59, and Luteolibacter had negative correlation with PFOA concentration. It assumed that the species of Thiobacillus and Sulfurimonas might be the PFOA contamination indicators or resistant strain in a certain concentration range of PFOA, which needs to be further studied. Lutimonas, Marinobacter, and Aequorivita with high correlation with XQ10 play key roles in marine environment. In the present study, only a single sampling point was investigated. It could be speculated that the bacterial community in sediment also shifted seasonally, and further investigations are needed to reveal the relationship between temporal dynamics of the community and concentrations of PFAAs.

\section{Conclusion}

According to our current knowledge, the relationship between bacterial community compositions in sediment and PFOA pollution evaluated by Illumina high-throughput sequencing and high concentration of PFOA ( $456.20 \mathrm{ng} / \mathrm{g} \mathrm{dw})$ can reduce the diversity of bacterial community. While the concentration of PFOA is below $100 \mathrm{ng} / \mathrm{g}$, no significant effect on microbial community structure is observed. Proteobacteria is the dominant phylum in all samples, while the abundance of Proteobacteria $(85.1 \%)$ in sample XQ5 is significantly higher when compared with other 9 samples with the abundance of class of $\varepsilon$-Proteobacteria (23.4\%), genera of Thiobacillus 
(22.9\%), and Sulfurimonas (21.1\%). Thiobacillus and Sulfurimonas are positively correlated with the concentration of PFOA, so it has the potential to be the resistant strain for PFOA contamination. The profound understanding of bacterial communities in Xiaoqing River will be helpful to understand the risk of PFAAs to ecosystem.

Acknowledgments This study was supported by the National Natural Science Foundation of China (nos. 41571478 and 41171394), the Key Research Program of the Chinese Academy of Sciences (no. KZZD-EWTZ-12), and the National Fundamental Field Study Program (no. 2013FY11110).

\section{References}

Abell GCJ, Bowman JP (2005) Colonization and community dynamics of class Flavobacteria on diatom detritus in experimental mesocosms based on Southern Ocean seawater. Fems Microbiology Ecology 53:379-391

Acosta-Martinez V, Dowd S, Sun Y, Allen V (2008) Tag-encoded pyrosequencing analysis of bacterial diversity in a single soil type as affected by management and land use. Soil Biol Biochem 40: 2762-2770

Acosta-Martinez V, Dowd SE, Sun Y, Wester D, Allen V (2010) Pyrosequencing analysis for characterization of soil bacterial populations as affected by an integrated livestock-cotton production system. Appl Soil Ecol 45:13-25

Ahrens L, Gerwinski W, Theobald N, Ebinghaus R (2010) Sources of polyfluoroalkyl compounds in the North Sea, Baltic Sea and Norwegian Sea: evidence from their spatial distribution in surface water. Mar Pollut Bull 60:255-260

Allegretti P, Furlong J, Donati E (2006) The role of higher polythionates in the reduction of chromium(VI) by Acidithiobacillus and Thiobacillus cultures. J Biotechnol 122:55-61

Bao J, Liu W, Liu L, Jin Y, Ran X, Zhang Z (2010) Perfluorinated compounds in urban river sediments from Guangzhou and Shanghai of China. Chemosphere 80:123-130

Bao J, Liu W, Liu L, Jin Y, Dai J, Ran X, Zhang Z, Tsuda S (2011) Perfluorinated compounds in the environment and the blood of residents living near fluorochemical plants in Fuxin, China. Environ Sci Technol 45:8075-8080

Bartram AK, Lynch MDJ, Stearns JC, Moreno-Hagelsieb G, Neufeld JD (2011) Generation of multimillion-sequence 16S rrna gene libraries from complex microbial communities by assembling paired-end Illumina reads. Appl Environ Microbiol 77:3846-3852

Bates ST, Berg-Lyons D, Caporaso JG, Walters WA, Knight R, Fierer N (2011) Examining the global distribution of dominant archaeal populations in soil. Isme Journal 5:908-917

Becker AM, Gerstmann S, Frank H (2008) Perfluorooctanoic acid and perfluorooctane sulfonate in the sediment of the Roter Main river, Bayreuth, Germany. Environ Pollut 156:818-820

Chen L, Wang L-y, S-j L, Hu J-y, He Y, H-w Z, X-h Z (2013) Profiling of microbial community during in situ remediation of volatile sulfide compounds in river sediment with nitrate by high throughput sequencing. Int Biodeter Biodegr 85:429-437

Corsolini S, Sarkar SK, Guerranti C, Bhattacharya BD, Rakshit D, Jonathan MP, Godhantaraman N (2012) Perfluorinated compounds in surficial sediments of the Ganges River and adjacent Sundarban mangrove wetland, India. Mar Pollut Bull 64:2829-2833

Dai J, Li M, Jin Y, Saito N, Xu M, Wei F (2006) Perfluorooctanesulfonate and perfluorooctanoate in red panda and giant panda from China. Environ Sci Technol 40:5647-5652
Edgar RC (2013) UPARSE: highly accurate OTU sequences from microbial amplicon reads. Nat Methods 10:996, -+

Gao J-F, Luo X, Wu G-X, Li T, Peng Y-Z (2013) Quantitative analyses of the composition and abundance of ammonia-oxidizing archaea and ammonia-oxidizing bacteria in eight full-scale biological wastewater treatment plants. Bioresour Technol 138:285-296

Gao J, Luo X, Wu G, Li T, Peng Y (2014) Abundance and diversity based on amoA genes of ammonia-oxidizing archaea and bacteria in ten wastewater treatment systems. Appl Microbiol Biotechnol 98:33393354

Hanson ML, Sibley PK, Brain RA, Mabury SA, Solomon KR (2005) Microcosm evaluation of the toxicity and risk to aquatic macrophytes from perfluorooctane sulfonic acid. Arch Environ Contam Toxicol 48:329-337

Hazelton PD, Cope WG, Pandolfo TJ, Mosher S, Strynar MJ, Barnhart MC, Bringolf RB (2012) Partial life-cycle and acute toxicity of perfluoroalkyl acids to freshwater mussels. Environ Toxicol Chem 31:1611-1620

Higgins CP, Field JA, Criddle CS, Luthy RG (2005) Quantitative determination of perfluorochemicals in sediments and domestic sludge. Environ Sci Technol 39:3946-3956

Hong Q, Meng Q, Wang P, Wang H, Liu R (2010) Regional aquatic ecological security assessment in Jinan, China. Aquat Ecosyst Health Manage 13:319-327

Huang K, Zhang X-X, Shi P, Wu B, Ren H (2014) A comprehensive insight into bacterial virulence in drinking water using 454 pyrosequencing and Illumina high-throughput sequencing. Ecotoxicol Environ Saf 109:15-21

Ibarbalz FM, Figuerola ELM, Erijman L (2013) Industrial activated sludge exhibit unique bacterial community composition at high taxonomic ranks. Water Res 47:3854-3864

Kawamoto K, Oashi T, Oami K, Liu W, Jin Y, Saito N, Sato I, Tsuda S (2010) Perfluorooctanoic acid (PFOA) but not perfluorooctane sulfonate (PFOS) showed DNA damage in comet assay on Paramecium caudatum. J Toxicol Sci 35:835-841

Kirchman DL (2002) The ecology of Cytophaga-Flavobacteria in aquatic environments. Fems Microbiology Ecology 39:91-100

Lau C, Anitole K, Hodes C, Lai D, Pfahles-Hutchens A, Seed J (2007) Perfluoroalkyl acids: a review of monitoring and toxicological findings. Toxicol Sci 99:366-394

Liu J, Avendano SM (2013) Microbial degradation of polyfluoroalkyl chemicals in the environment: a review. Environ Int 61:98-114

Lu L, Xing D, Ren N (2012) Pyrosequencing reveals highly diverse microbial communities in microbial electrolysis cells involved in enhanced $\mathrm{H}-2$ production from waste activated sludge. Water Res 46:2425-2434

Ma M, Feng Z, Guan C, Ma Y, Xu H, Li H (2001) DDT, PAH and PCB in sediments from the intertidal zone of the Bohai Sea and the Yellow Sea. Mar Pollut Bull 42:132-136

Ma Q, Qu Y, Shen W, Zhang Z, Wang J, Liu Z, Li D, Li H, Zhou J (2015) Bacterial community compositions of coking wastewater treatment plants in steel industry revealed by Illumina high-throughput sequencing. Bioresour Technol 179:436-443

Magoc T, Salzberg SL (2011) FLASH: fast length adjustment of short reads to improve genome assemblies. Bioinformatics 27:2957-2963

Matochko WL, Chu KK, Jin BJ, Lee SW, Whitesides GM, Derda R (2012) Deep sequencing analysis of phage libraries using Illumina platform. Methods 58:47-55

Moody CA, Martin JW, Kwan WC, Muir DCG, Mabury SC (2002) Monitoring perfluorinated surfactants in biota and surface water samples following an accidental release of fire-fighting foam into Etobicoke Creek. Environ Sci Technol 36:545-551

Naile JE, Khim JS, Wang T, Chen C, Luo W, Kwon B-O, Park J, Koh CH, Jones PD, Lu Y, Giesy JP (2010) Perfluorinated compounds in water, sediment, soil and biota from estuarine and coastal areas of Korea. Environ Pollut 158:1237-1244 
Naile JE, Khim JS, Hong S, Park J, Kwon B-O, Ryu JS, Hwang JH, Jones PD, Giesy JP (2013) Distributions and bioconcentration characteristics of perfluorinated compounds in environmental samples collected from the west coast of Korea. Chemosphere 90:387-394

Nikolov L, Karamanev D, Mamatarkova V, Mehochev D, Dimitrov D (2002) Properties of the biofilm of Thiobacillus ferrooxidans formed in rotating biological contactor. Biochem Eng J 12:43-48

Okabe S, Odagiri M, Ito T, Satoh H (2007) Succession of sulfur-oxidizing bacteria in the microbial community on corroding concrete in sewer systems. Appl Environ Microbiol 73:971-980

Olsen GW, Butenhoff JL, Zobel LR (2009) Perfluoroalkyl chemicals and human fetal development: an epidemiologic review with clinical and toxicological perspectives. Reprod Toxicol 27:212-230

Ongley ED, Zhang X, Yu T (2010) Current status of agricultural and rural non-point source pollution assessment in China. Environ Pollut 158: $1159-1168$

Paul AG, Jones KC, Sweetman AJ (2009) A first global production, emission, and environmental inventory for perfluorooctane sulfonate. Environ Sci Technol 43:386-392

Puth MT, Neuhäusera M, Ruxton GD (2015) Effective use of Spearman's and Kendall's correlation coefficients for association between two measured traits. Anim Behav 102:77-84

Rayne S, Forest K (2009) Perfluoroalkyl sulfonic and carboxylic acids: a critical review of physicochemical properties, levels and patterns in waters and wastewaters, and treatment methods. J Environ Sci Health A 44:1145-1199

Roberts DJ, Nica D, Zuo G, Davis JL (2002) Quantifying microbially induced deterioration of concrete: initial studies. Int Biodeter Biodegr 49:227-234

Roeske K, Sachse R, Scheerer C, Roeske I (2012) Microbial diversity and composition of the sediment in the drinking water reservoir Saidenbach (Saxonia, Germany). Syst Appl Microbiol 35:35-44

Saenz de Miera LE, Arroyo P, de Luis CE, Falagan J, Ansola G (2014) High-throughput sequencing of 16S RNA genes of soil bacterial communities from a naturally occurring $\mathrm{CO} 2$ gas vent. International Journal of Greenhouse Gas Control 29:176-184

Senthilkumar K, Ohi E, Sajwan K, Takasuga T, Kannan K (2007) Perfluorinated compounds in river water, river sediment, market fish, and wildlife samples from Japan. Bull Environ Contam Toxicol 79:427-431

Torrentó C, Cama J, Urmeneta J, Otero N, Soler A (2010) Denitrification of groundwater with pyrite and Thiobacillus denitrificans. Chem Geol 278:80-91

Vidyalakshmi R, Paranthaman R, Bhakyaraj R (2009) Sulphur oxidizing bacteria and pulse nutrition-a review. World Journal of Agricultural Sciences 5:270-278
Wang T, Wang Y, Liao C, Cai Y, Jiang G (2009) Perspectives on the inclusion of perfluorooctane sulfonate into the Stockholm Convention on persistent organic pollutants. Environ Sci Technol 43:5171-5175

Wang T, Lu Y, Chen C, Naile JE, Khim JS, Park J, Luo W, Jiao W, Hu W, Giesy JP (2011) Perfluorinated compounds in estuarine and coastal areas of north Bohai Sea, China. Mar Pollut Bull 62:1905-1914

Wang Y, Sheng H-F, He Y, Wu J-Y, Jiang Y-X, Tam NF-Y, Zhou H-W (2012) Comparison of the levels of bacterial diversity in freshwater, intertidal wetland, and marine sediments by using millions of Illumina tags. Appl Environ Microbiol 78:8264-8271

Wang L, Liu L, Zheng B, Zhu Y, Wang X (2013a) Analysis of the bacterial community in the two typical intertidal sediments of Bohai Bay, China by pyrosequencing. Mar Pollut Bull 72:181-187

Wang P, Wang T, Giesy JP, Lu Y (2013b) Perfluorinated compounds in soils from Liaodong Bay with concentrated fluorine industry parks in China. Chemosphere 91:751-757

Wang L, Zheng B, Nan B, Hu P (2014a) Diversity of bacterial community and detection of nirS- and nirK-encoding denitrifying bacteria in sandy intertidal sediments along Laizhou Bay of Bohai Sea, China. Mar Pollut Bull 88:215-223

Wang P, Lu Y, Wang T, Fu Y, Zhu Z, Liu S, Xie S, Xiao Y, Giesy JP (2014b) Occurrence and transport of 17 perfluoroalkyl acids in 12 coastal rivers in south Bohai coastal region of China with concentrated fluoropolymer facilities. Environ Pollut 190:115-122

Wang XP, Halsall C, Codling G, Xie ZY, Xu BQ, Zhao Z, Xue YG, Ebinghaus R, Jones KC (2014c) Accumulation of perfluoroalkyl compounds in Tibetan Mountain Snow: temporal patterns from 1980 to 2010. Environ Sci Technol 48:173-181

Yousefi A, Allahverdi A, Hejazi P (2014) Accelerated biodegradation of cured cement paste by Thiobacillus species under simulation condition. Int Biodeter Biodegr 86(Part C):317-326

Yu D, Mao H (2002) Regional carrying capacity: case studies of Bohai Rim area. J Geogr Sci 12:177-185

Zamora L, Vela AI, Sanchez-Porro C, Palacios MA, Dominguez L, Moore ERB, Ventosa A, Fernandez-Garayzabal JF (2013) Characterization of flavobacteria possibly associated with fish and fish farm environment. Description of three novel Flavobacterium species: Flavobacterium collinsii sp nov., Flavobacterium branchiarum sp nov., and Flavobacterium branchiicola sp nov. Aquaculture 416:346-353

Zhang P, Song J, Yuan H (2009) Persistent organic pollutant residues in the sediments and mollusks from the Bohai Sea coastal areas, North China: An overview. Environ Int 35:632-646

Zhu Z, Wang T, Wang P, Lu Y, Giesy JP (2014) Perfluoroalkyl and polyfluoroalkyl substances in sediments from South Bohai coastal watersheds, China. Mar Pollut Bull 85:619-627 